\title{
A review of filamin A mutations and associated interstitial lung disease
}

\author{
Erina Sasaki ${ }^{1}$ (D) Angela T. Byrne ${ }^{2} \cdot$ Ethna Phelan $^{2} \cdot$ Desmond W. Cox $^{3,4} \cdot$ William Reardon $^{1}$ \\ Received: 25 September 2018 / Revised: 22 November 2018 / Accepted: 26 November 2018 / Published online: 13 December 2018 \\ (C) Springer-Verlag GmbH Germany, part of Springer Nature 2018
}

\begin{abstract}
The filamin A gene (FLNA) on Xq28 encodes the filamin A protein. Mutation in FLNA causes a wide spectrum of disease including skeletal dysplasia, neuronal migration abnormality, cardiovascular malformation, intellectual disability and intestinal obstruction. Recently, childhood-onset interstitial lung disease associated with a range of FLNA mutations has been recognised and reported. We document our personal experience of this emerging disorder and compile a comprehensive overview of clinical features and molecular changes in all identifiable published cases. Reviewing the emerging dataset, we underline this unanticipated phenotypic consequence of pathogenic FLNA mutation-associated pulmonary disease.

Conclusion: From the emerging data, we suggest that while reviewing complex cases with a sustained oxygen requirement against a clincial background of cardiac concerns or intestinal obstruction to have a high index of suspicion for FLNA related pathology and to instigate early MRI brain scan and FLNA mutation analysis.

\section{What is Known:}

- FLNA gene on Xq28 encodes the filamin A protein and mutation therein is associated with variable phenotypes depending on its nature of mutation. - Loss-of-function mutation of filamin A is associated with X-linked inherited form of periventricular nodular heterotopia with or without epilepsy with most individuals affected being female. There is a recently recognised associated respiratory phenotype.

What is New:

- The respiratory phenotype in the form of childhood interstitial lung disease is a recently recognised clinical consequence of loss-of-function FLNA mutation.

- Rare male patients with loss-of-function FLNA mutation-associated lung disease with residual protein function can survive into infancy with a severe form of the phenotype.
\end{abstract}

Keywords FLNA · Childhood interstitial lung disease · Periventricular nodular heterotopia · Persistent pulmonary hypertension · Lung transplant

$\begin{array}{ll}\text { Abbreviations } \\ \text { FLNA } & \text { Filamin A } \\ \text { PNH } & \text { Periventricular nodular heterotopia } \\ \text { OMIM } & \text { Online Mendelian Inheritance in Man } \\ \text { NG } & \text { Nasogastric } \\ \text { PDA } & \text { Patent ductus arteriosus }\end{array}$

Communicated by Peter de Winter

Erina Sasaki

sasakierina06@gmail.com

1 Clinical Genetics Department, Our Lady's Children's Hospital, Dublin, Ireland

2 Paediatric Radiology Department, Our Lady's Children's Hospital, Dublin, Ireland

3 Paediatric Respiratory Department, Our Lady's Children's Hospital, Dublin, Ireland

4 School of Medicine, University College Dublin, Dublin, Ireland
UPD Uni-parental disomy

HRCT High-resolution computed tomography

\section{Introduction}

No clinical geneticist can be untouched by filamin A (FLNA, OMIM 300049) related disease. FLNA gene on Xq28 encodes the filamin A protein. Filamin A is a widely expressed $280-\mathrm{kD}$ actin-binding protein that regulates reorganisation of the actin cytoskeleton by interacting with integrins, transmembrane receptors complexes and second messengers. Cell motility, adhesion, polarisation and division depend on dynamic regulation of the actin cytoskeleton [1].

Loss-of-function mutations cause an X chromosome dominantly inherited form of periventricular nodular heterotopia (PNH), mainly seen in females [2]. Occasional male cases of $\mathrm{PNH}$ are also recorded, thought to reflect residual protein function $[3,4]$. By contrast, missense mutations or in-frame 
deletions result in skeletal phenotypes including MelnickNeedles syndrome and Oto-Palato-Digital syndromes Types I and II [5]. Other phenotypes of FLNA mutation include PNH and frontometaphyseal dysplasia [6] and X-linked cardiac valvular dysplasia [7] but the spectrum of associated diseases extends to intestinal pseudo-obstruction [8] as well as to cases of intellectual disability [9] and bowel abnormalities [4].

Perhaps a less widely recognised clinical consequence of FLNA mutation is the emergence in the last few years of an associated respiratory phenotype. To date, we believe there have been 16 such cases reported [10-17]. Based on published reports, the elements of this respiratory presentation comprise of multi-lobar hyperinflation and pulmonary vascular attenuation. The clinical outcome has been variable, with four deaths reported. Pathological findings are consistent with emphysematous changes and pulmonary arteriopathy. A few cases have been treated with lung transplantation [16].

Childhood interstitial lung disease (chILD) represents a heterogenous group of pulmonary disorders with abnormal lung interstitium and distal airspaces resulting in abnormal gas exchange. chILD is rare with an estimated prevalence of $<1$ per 100,000 children and comprises of more than 200 different conditions with a variety of proposed classifications $[18,19]$. The diagnosis and classification of chILD remains a challenge and differs greatly when compared with adult-onset ILD in terms of pathology and clinical progress [20]. Because of the rarity of these conditions, research in the area has been lacking and knowledge outside of highly specialist paediatric centres is poor.

Arising from our observation of the pulmonary phenotype in two new cases, we have reviewed the emerging dataset and now summarise the extant knowledge and experience of this surprising FLNA mutation-associated disease.

\section{Materials and methods}

A medical literature review of previously reported patients, and two additional cases from our institute, with childhood interstitial lung disease associated with FLNA mutation [10-17] was conducted. The clinical presentation, radiological features, mutation variants, management and outcome were compiled and compared (Table 1).

\section{Patient medical report}

Case one A 4-week-old female infant presented to the emergency department with fever, poor feeding and lethargy. She was admitted for suspected sepsis and received antibiotics. Septic workup was negative, including nasopharyngeal aspirates.

Several episodes of profound desaturation were observed with oxygen saturation falling to $75-80 \%$ in room air as a result of which she was commenced on nasal cannula $\mathrm{O}_{2}$
(0.1-0.2 L/min). Expert respiratory assessment as well as speech and language review was undertaken for her persistent respiratory symptoms and oxygen requirement. The video fluoroscopy showed a mild degree of gastroesophageal reflux and aspiration. As her feeding, particularly intake volume, had also deteriorated, even prior to the admission, she was commenced on thickened feeds via nasogastric (NG) tube feeding.

This patient was one of a pair of twins and born to a couple who had in vitro fertilisation (IVF) with donor ova and paternal sperm. Pre-IVF treatment karyotype on the parents showed the father has balanced Robertsonian translocation on chromosomes 13 and 14 (45 XY der(13;14)(q10;q10)) and his wife has $47 \mathrm{XXX}(2) / 46 \mathrm{XX}(48)$ mosaicism. No data of the biological mother (donor) was available at the time. The parents reported that three fertilised ova were implanted and one male fetus demised at around 8 weeks. The twins were delivered at 37 weeks gestation by elective Caesarean section for breech presentation. Both neonates were well at delivery and did not require resuscitation. Twin two (the patient) was $2.6 \mathrm{~kg}$ at birth, on the 25th percentile. Twin one, a male, is asymptomatic.

On re-examination at 6 weeks of age, her head circumference measured $35.8 \mathrm{~cm}$ on the 9 th percentile, weight $3.96 \mathrm{~kg}$ on the 9th percentile, length $54.5 \mathrm{~cm}$ on the 50 th percentile. She was mildly tachypnoeic and saturating $95-100 \%$ on $0.2 \mathrm{~L} / \mathrm{min}$ oxygen via nasal cannula. She was alert and nondysmorphic. Clinical examination was normal-specifically, there was no tongue fasciculation. Tone was appropriate centrally and peripherally.

Echocardiogram showed a small atrial septum defect, $4 \mathrm{~mm}$, with left to right shunt, but otherwise normal heart. Initial chest radiograph at presentation demonstrated well-aerated lungs with minor bronchial wall thickening, and no coat hanger profile. CT thorax was requested and showed diffuse bilateral ground-glass opacification throughout the lungs, interstitial thickening and cystic changes raising the possibility of childhood interstitial lung disease (Fig. 1). Cranial ultrasound, undertaken to investigate possible intracranial bleeding, showed unusual morphology of the frontal horns and radiological suspicion of bilateral cortical heterotopia was confirmed on MRI scan, which showed periventricular nodular heterotopia with a single nodule into the right temporal horn (Fig. 1).

Assessment by a clinical genetics consultant led to DNA analysis for FLNA, as well as karyotyping to rule out paternally derived UPD 14, which could arise from the father's Robertsonian translocation. UPD studies confirmed biparental inheritance of chromosome 14, while a pathogenic frameshift, heterozygous loss-of-function variant in FLNA gene c.1709 1712 del p.(Val570Alafs*105) was identified. Subsequent analysis in the biological mother confirms the presence of the mutation. The patient was discharged on home oxygen and azithromycin prophylaxis. A follow-up video fluoroscopy at 7 months demonstrated no aspiration. The patient is slowly being weaned off NG feeds onto oral feeds. Her most 


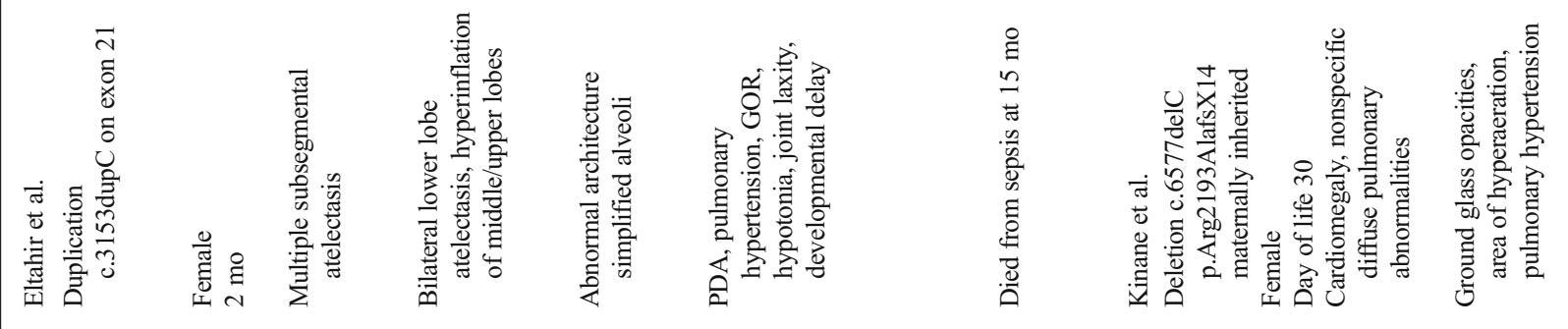

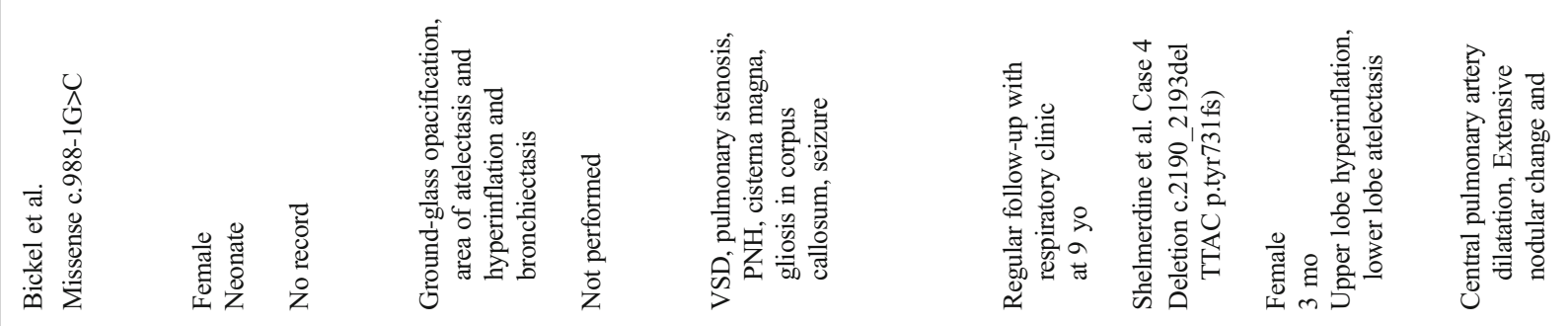
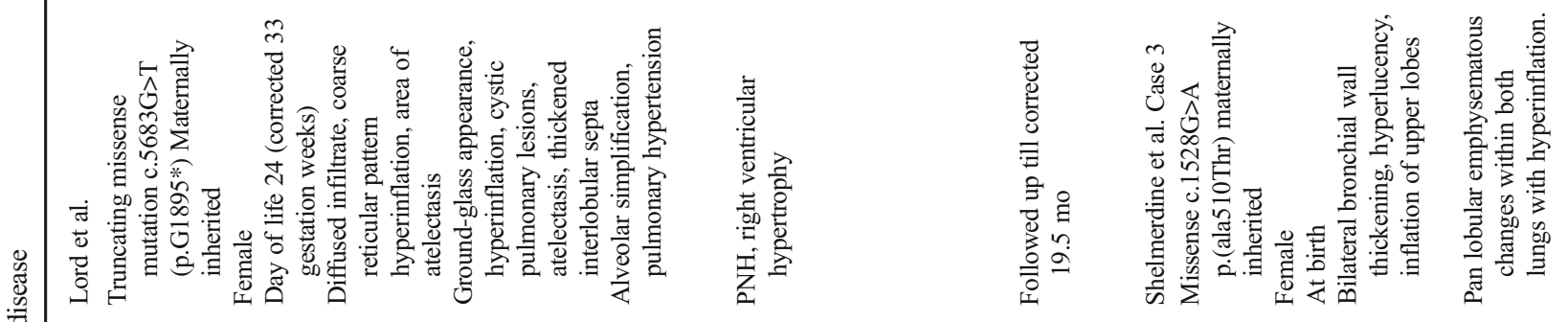

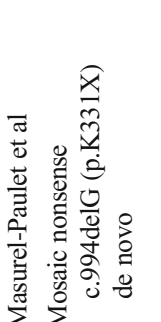

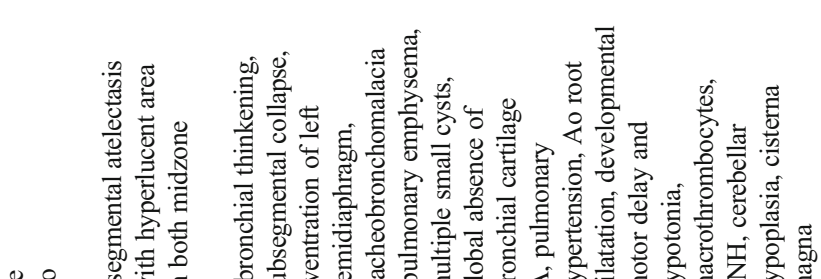

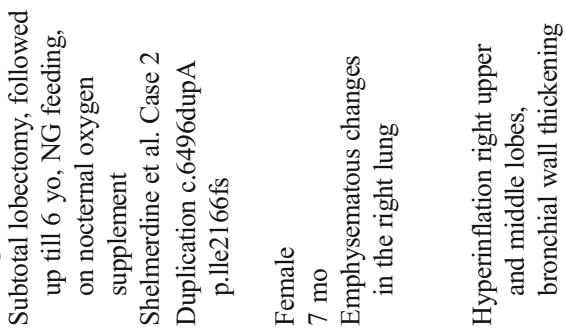

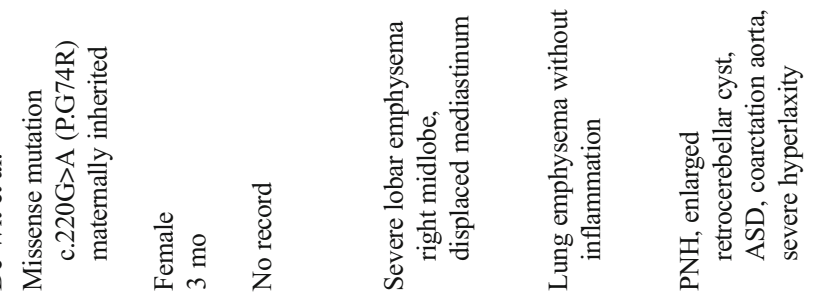
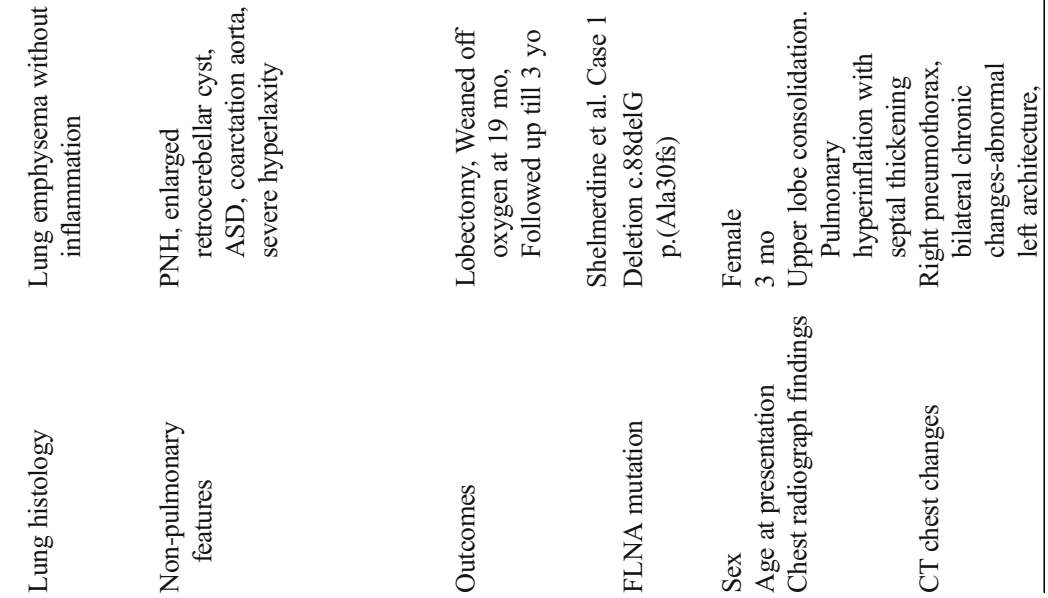

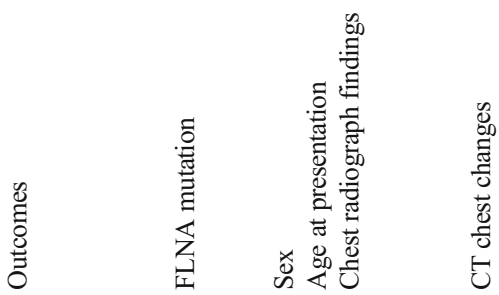



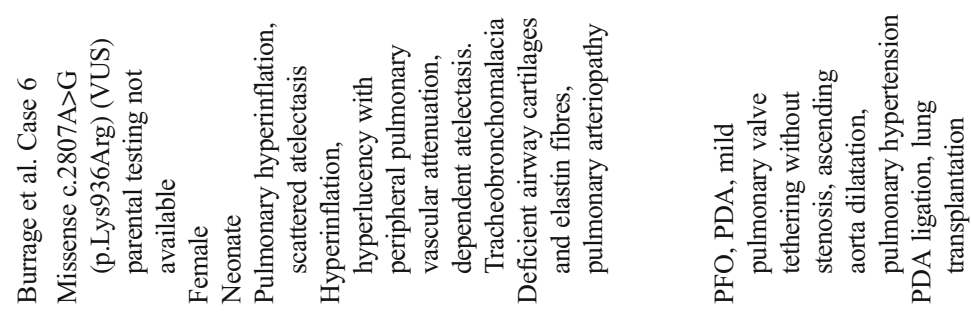

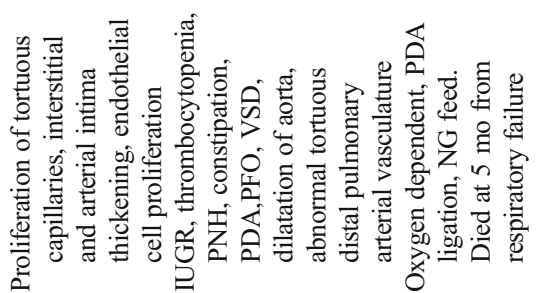

籍

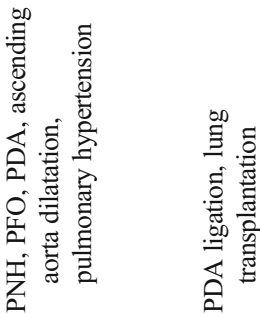

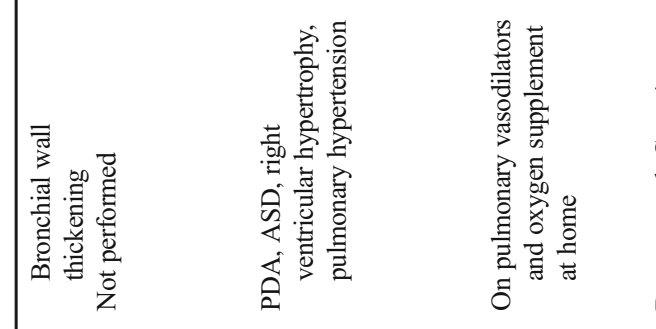

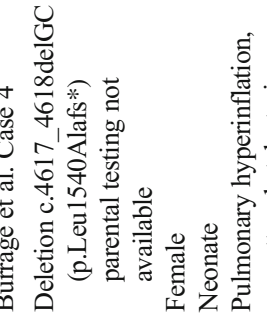

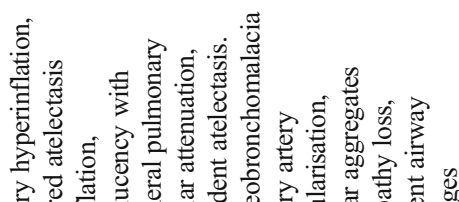

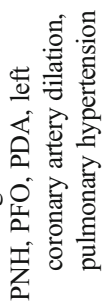

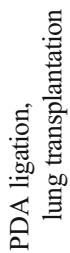

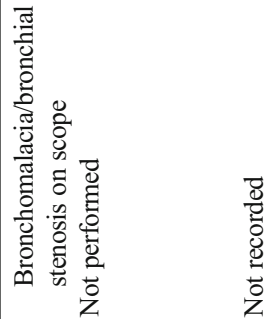

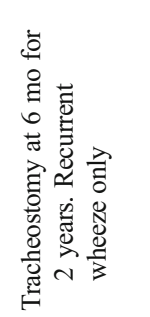

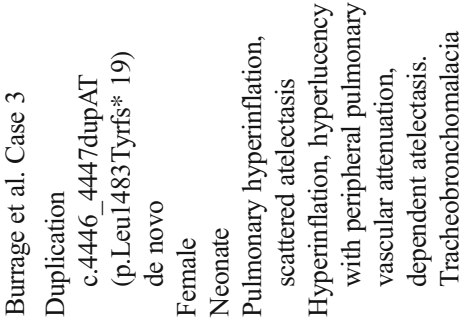

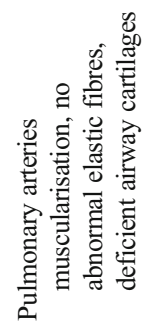

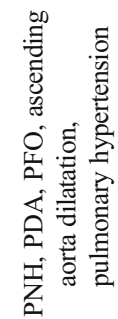

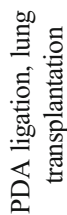

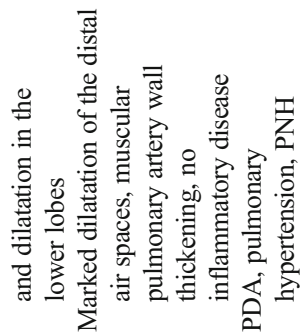

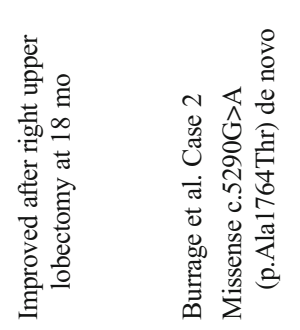

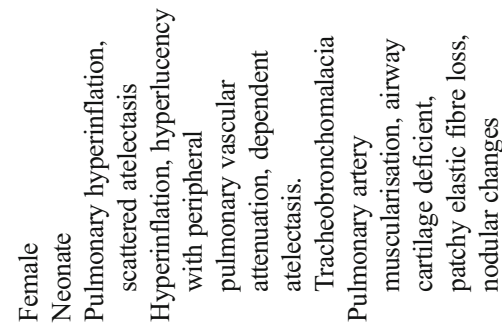

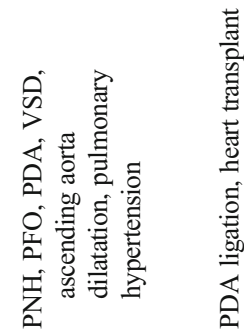

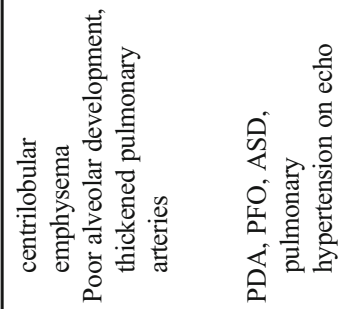

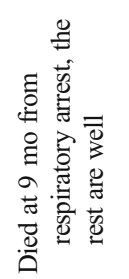

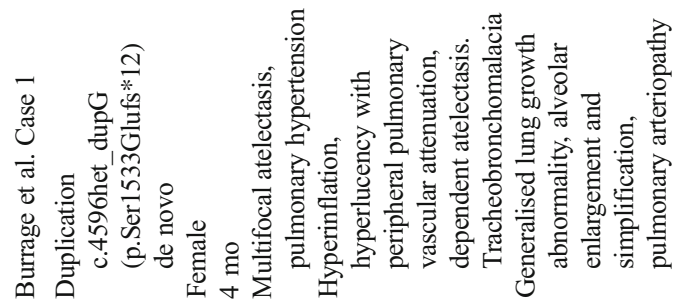

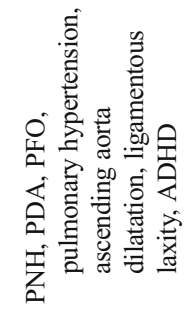
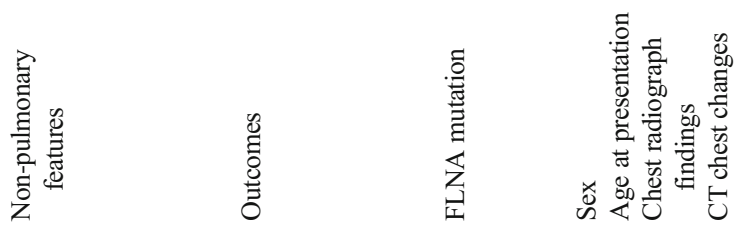

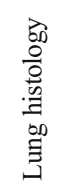

总

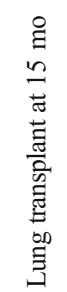




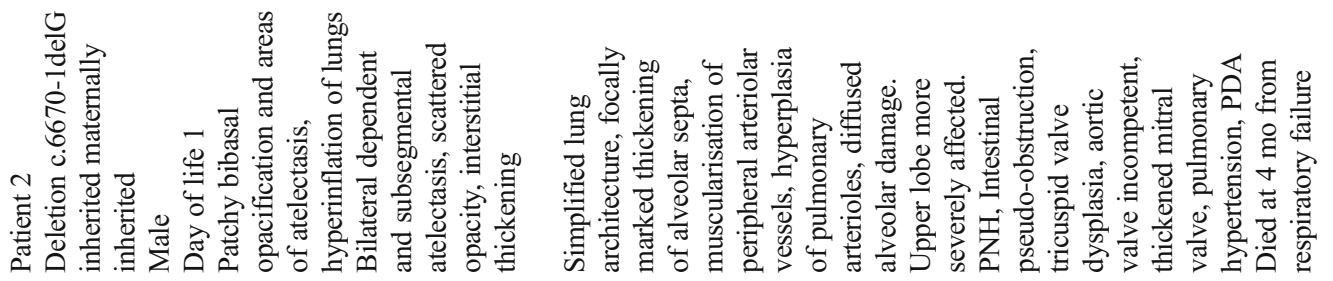

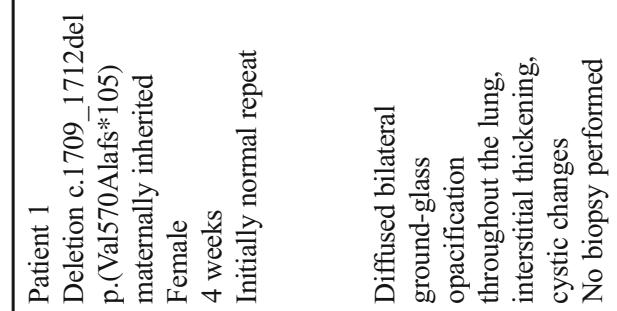
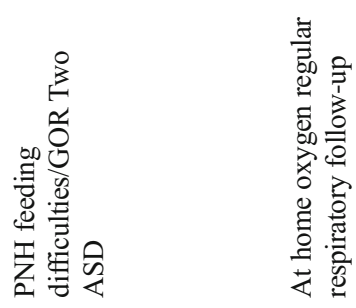

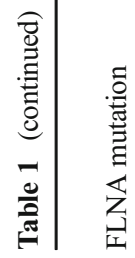
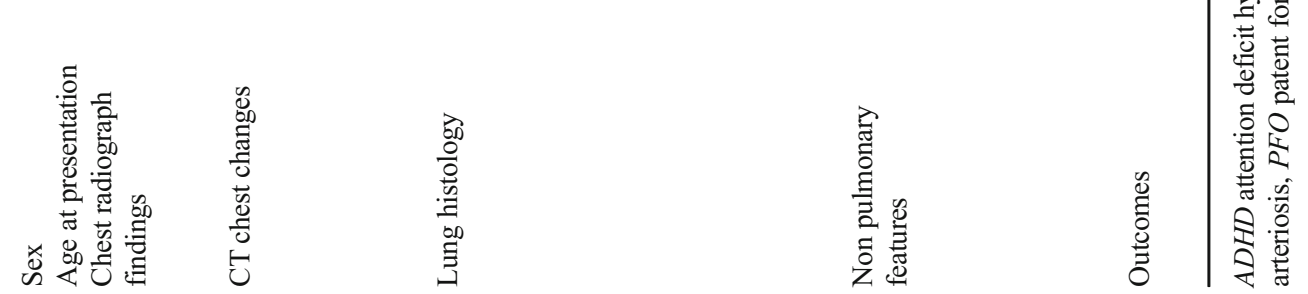

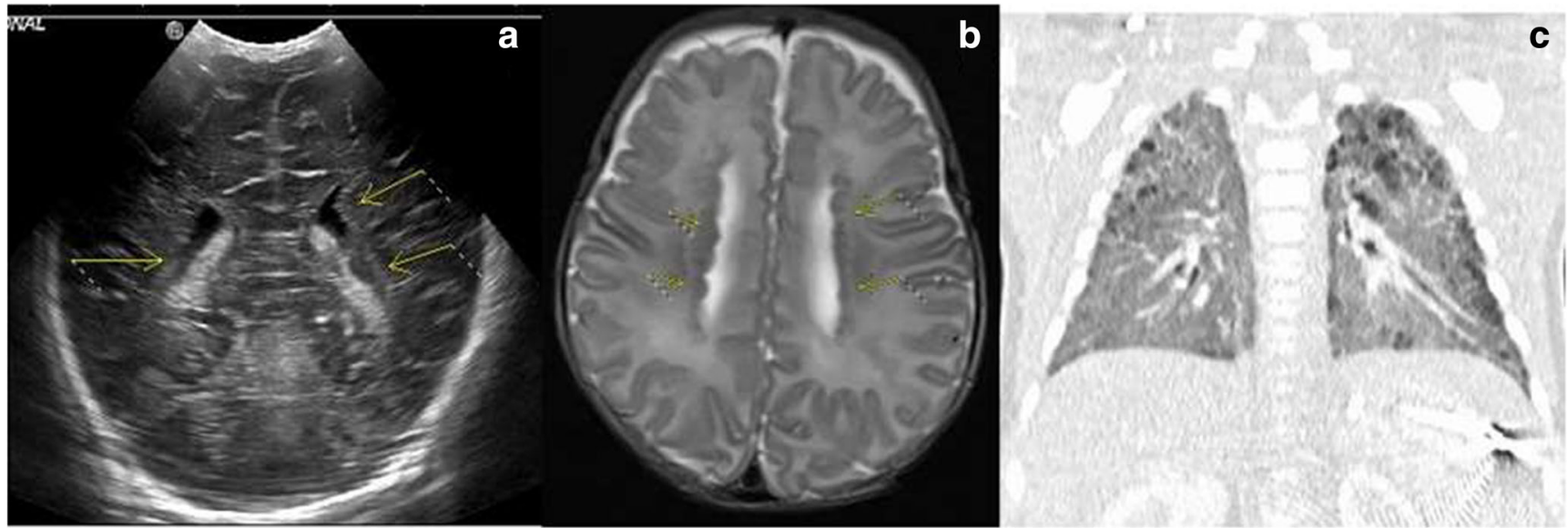

Fig. 1 (a) The ultrasound finding of indentations along the lateral ventricles (arrowed) suggest nodular heterotopia and were subsequently corroborated by MRI. (b) Axial MRI T2 imaging of the brain which shows multiple foci of periventricular nodular heterotopia bilaterally

recent chest radiograph shows hyperinflated lung fields bilaterally. The patient continues to require $0.2 \mathrm{~L} / \mathrm{min}$ of oxygen at home and remains clinically stable at the age of 11 months.

Case two A male neonate born to non-consanguineous parents at full term. Birth weight was $3.4 \mathrm{~kg}$ on the 50th percentile and head circumference was $35 \mathrm{~cm}$ on the 50th percentile. He became cyanotic on day 1 of life. Increased precordial activity was noted clinically, and a loud cardiac murmur was heard. Oxygen saturation in room air fell to $90 \%$. Chest radiograph on day one of life showed cardiomegaly and nonspecific hazy opacification in both lungs. The patient was transferred to a tertiary hospital for further assessment and management in the paediatric intensive care unit as he required assisted ventilation. The echocardiogram showed a dysplastic tricuspid valve with moderate regurgitation, right atrial dilatation, pulmonary hypertension, large patent ductus arteriosus (PDA), aortic valve incompetent and thickened mitral valve.

The patient was the 5th live infant to his mother who was aged 32. She had a difficult obstetric history with four surviving children. She had experienced four miscarriages between 8 and 12 weeks gestation. This pregnancy had pursued a normal course until 32 weeks, when ultrasound review had shown mild dilated lateral ventricles, large cisterna magna and dilated loops of the bowel. The patient was born by normal delivery at 38 weeks gestation. Noteworthy aspects of the family history were that the patient's sister died at 11 months old of hypoplastic left heart. His maternal uncle had died at 3 years of age with congenital heart disease. There is another maternal uncle who has valvular heart disease and learning difficulties in adult life.

Clinical examination confirmed a distended abdomen with visible loops of the bowel on ultrasound and plain film and suspected anal stenosis for which treatment by anal dilatation was unsuccessful. There was slow gut emptying and delayed transit of contrast media. Putative surgical diagnoses of (arrowed). (c) Coronal CT Chest demonstrates diffuse bilateral groundglass opacification, interstitial thickening and subpleural and parenchymal lung cysts

necrotising enterocolitis or malrotation were not supported radiologically.

Karyotype and microarray, undertaken by non-geneticists, were normal. Suction biopsy of the rectum showed ganglionic bowel, with no evidence of Hirschsprung's disease. Renal ultrasonography was normal. While cranial ultrasonography was normal, MRI revealed a nodular focus in the wall of the right lateral ventricle. The appearance was consistent with periventricular nodular heterotopia (Fig. 2).

$\mathrm{He}$ remained intubated and ventilator dependent until age 4 months. Chest radiographs showed persistent interstitial opacification in both lungs and minor pleural effusions. CT thorax showed bilateral interstitial and septal thickening with some small patches of ground-glass opacification and atelectasis (Fig. 2).

His pulmonary hypertension remained significantly elevated with pulmonary artery pressures recording supra-systemic pressures on maximal ventilator support. A decision was made to withdraw respiratory support and he died at 4 months of age.

Post-mortem examination was consistent with death from respiratory insufficiency reflected in severe pulmonary hypertensive vasculopathy. Both lungs had a cystic appearance over the anterior surface with small bullae ranging from 0.3 to $0.8 \mathrm{~cm}$ in size. There was diffuse alveolar damage.

FLNA analysis confirmed a hemizygous mutation of a splice acceptor site c.6670-1delG, predicted to result in aberrant mRNA production and nonsense-mediated mRNA decay. A pedigree study showed his mother is a heterozygous carrier of this mutation, as are the mother's siblings.

\section{Results}

All the patients who had chest radiograph showed characteristic findings: hyperinflation of the lungs with scattered 


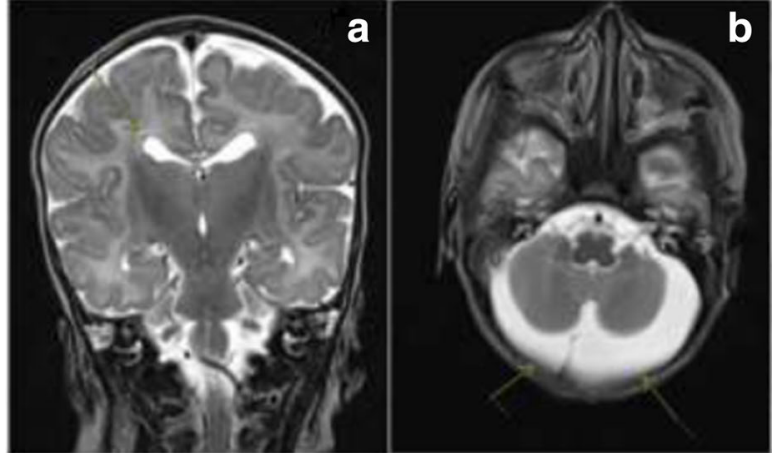

Fig. 2 (a) Coronal T2 imaging of the brain shows a small nodule of grey matter heterotopia (arrowed) adjacent to the frontal horn of the right lateral ventricle. (b) Axial T2 imaging showing mega cisterna magna (arrowed).(c) Coronal CT Thorax demonstrates interlobular septal thickening bilaterally as seen in chronic lung disease with some sparing of the

atelectasis. This appearance mimics pulmonary emphysema and bronchopulmonary dysplasia. These changes are progressive, as is evident on serial studies. CT thorax showed widespread peribronchial and interlobular septal thickening, ground-glass opacification appearance, areas of hyperinflation, heterogenous cystic lesion and atelectasis, in both our cases and, insofar as can be established, in published cases.

Twelve out of 18 patients (16 published and the 2 under report) had PDA; 14 out of 18 had pulmonary hypertension reported on echocardiogram. Fourteen patients had MRI brain, all demonstrating periventricular nodular heterotopia. There was no record of constipation or bowel obstruction in the published cases [10-17].

Several of the reported cases had the diagnosis of FLNA gene mutation made following atypical presentation of diffuse lung disease $[14,15]$. The usual clinical course comprises a respiratory presentation such as late-onset bronchopulmonary dysplasia (BPD) like symptoms in a term infant.

While the exact role of FLNA in normal lung physiology is not currently understood, it is pertinent to observe the expression studies of FLNA protein in murine alveoli [21]. This proves the importance of FLNA protein to the normal development of the alveoli in embryological life, and the cases we present here manifest the clinical consequence in alveolar pathology arising from FLNA mutation with loss of the contribution to the normal embryological alveolar development which attends FLNA protein.

Multisystem review and brain MRI scan is the usual prompt for FLNA analysis, following the identification of periventricular nodular heterotopia $[10-12,17]$. To date, the FLNA mutations described in other patients with an FLNA mutation-associated respiratory phenotype comprise four deletions, six missense changes, five duplications and one nonsense pathogenic variant. Seven variants were reported to result in loss of function, in common with our cases. Of the 11 cases that underwent family screening, seven were shown to have been maternally inherited, as is the case in both the cases we observe (Table 1). c

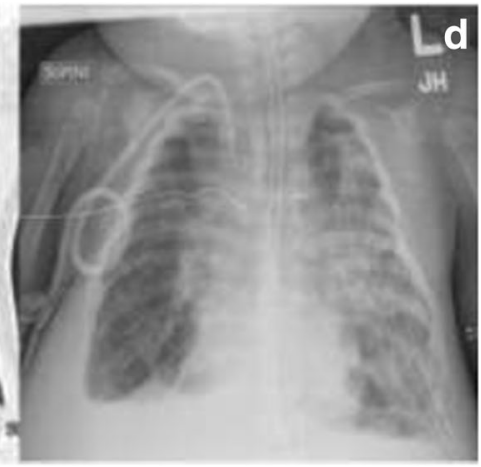

left lower lobe. Dependant atelectasis is also present (d) The lungs are hyperinflated and there is a small left apical pneumothorax. There are patchy opacities bilaterally, worse on the left in keeping with consolidation on a background of chronic lung disease. Pleural thickening at both costophrenic angles.

\section{Discussion}

That mutation in FLNA causes variable clinical features of skeletal, cardiac, neurological and neuroradiological dysfunction is well established over the last 20 years in the study of human disease. However, nothing in the profile of the diseases and disorders which we now know to be associated with FLNA mutation has predicted the emergence in recent times of a pulmonary disease phenotype. That this is a real and significant finding in respect of FLNA mutation is based on the 16 cases reported to date (some cases may, possibly, have been the subject of two reports, so exact quantification is not reliable) and our further two cases, to support the pathogenic FLNA mutation and associated progressive respiratory disease and hypoxemia manifesting in early infancy with substantial heterogeneity in severity and outcome.

Childhood interstitial lung disease (chILD) is a heterogenous group of disorders originating from genetic, immunological and lung developmental abnormalities resulting in abnormalities of the lung interstitium and disordered gas exchange [18]. The diagnosis and classification of chILD remains a challenge as chILD is rare and much more diverse than adult-onset ILD [20]. Most cases of chILD present during infancy and the diagnosis should be suspected in any term neonate presenting with unexplained respiratory distress such as in the cases of the two patients presented here [20].

Both cases we report manifest typical clinical symptoms and radiological findings of FLNA-related respiratory disease, in the context of FLNA mutations, both resulting in loss of function of the protein. There is no suggestion that these mutations cluster to a specific region of FLNA gene. Our first patient in the clinical report here, in common with several other FLNA-associated chronic lung disease patients reported previously, mostly female, did well at birth and in the newborn period, becoming symptomatic at age 4 weeks. Thereafter, progressive respiratory problems, such as cough, increased work of breathing, dyspnoea at feeding and related weight 
loss, became significant and required oxygen supplementation therapy. The general experience among reported cases appears to be fairly variable, some, like in this female case, managing with oxygen support, others dying of severe respiratory disease or even being offered lung transplantation (Table 1).

There were differences between the two cases reported here in terms of their findings on HRCT thorax. Where the chest imaging on our first case demonstrated more subtle cystic and diffuse ground-glass changes, the imaging on our second case demonstrated more striking hyperinflation and emphysematous changes as other case series have reported [12-15, 17]. Over time, hyperinflation and emphysematous changes developed on follow-up chest $\mathrm{X}$ rays in the first case which suggests that the CT thorax was performed early on in the evolution of this condition. This would explain why there are differences in the pattern of abnormalities seen on initial chest imaging in both cases.

Pulmonary aspiration may have been a confounding feature in the first case. However, the severity and diffuse nature of the interstitial changes seen on initial chest imaging could not be explained by aspiration alone. The male patient, reported here, presented with persistent significant pulmonary arterial hypertension, congenital cardiac malformation and abdominal distension/constipation. Persistent increased intestinal transit time (contrast study showed more than 5 days of emptying barium swallowed) was observed in him without any obvious radiologically or histologically identifiable obstruction or evidence of Hirschsprung's disease. Post-mortem examination confirmed no obstruction. This likely represents chronic intestinal pseudo-obstruction associated with loss-offunction mutation in FLNA described previously [4, 8]. In contrast to the female patient described here, he demonstrated a severe form of FLNA-associated disease with multi-organ malformations including the cardiac, respiratory, central nervous and gastrointestinal systems.

From emerging data, it would be wise for clinical geneticists invited to review complex cases with a sustained oxygen requirement against a clinical background of cardiac concerns or intestinal obstruction to have a high index of suspicion for $F L N$-related pathology and to instigate early MRI brain scan and FLNA mutation analysis.

Authors' contributions W.R and DW.C conceived the presenting review. E.S took lead in data collection and writing the manuscript with support of DW.C and W.R. AT.B and E.P supported analysing data. All authors provided critical feedback and helped shape the analysis and manuscript.

Compliance with ethical standardsPatient details are published with consent.

Conflict of interest The authors declare that they have no conflict of interest.

\section{References}

1. Robertson SP (2005) Filamin A: phenotypic diversity. Curr Opin Genet Dev 15:301-307. https://doi.org/10.1016/j.gde.2005.04.001

2. Fox JW, Lamperti ED, Ekșioğlu YZ, Hong SE, Feng Y, Graham DA, Scheffer IE, Dobyns WB, Hirsch BA, Radtke RA, Berkovic SF, Huttenlocher PR, Walsh CA (1998) Mutations in filamin 1 prevent migration of cerebral cortical neurons in human periventricular heterotopia. Neuron 21:1315-1325

3. Sheen VL, Dixon PH, Fox JW, Hong SE, Kinton L, Sisodiya SM, Duncan JS, Dubeau F, Scheffer IE, Schachter SC, Wilner A, Henchy R, Crino P, Kamuro K, DiMario F, Berg M, Kuzniecky R, Cole AJ, Bromfield E, Biber M, Schomer D, Wheless J, Silver K, Mochida GH, Berkovic SF, Andermann F, Andermann E, Dobyns WB, Wood NW, Walsh CA (2001) Mutations in the Xlinked filamin 1 gene cause periventricular nodular heterotopia in males as well as in females. Hum Mol Genet 10:1775-1783

4. Hehr U, Hehr A, Uyanik G, Phelan E, Winkler J, Reardon W (2006) A filamin A splice mutation resulting in a syndrome of facial dysmorphism, periventricular nodular heterotopia, and severe constipation reminiscent of cerebro-fronto-facial syndrome. J Med Genet 43:541-544. https://doi.org/10.1136/jmg.2005.038505

5. Robertson SP, Twigg SR, Sutherland-Smith AJ, Biancalana V, Gorlin RJ, Horn D, Kenwrick SJ, Kim CA, Morava E, NewburyEcob R, Orstavik KH, Quarrell OW, Schwartz CE, Shears DJ, Suri M, Kendrick-Jones J, Wilkie AO (2003) Localized mutations in the gene encoding the cytoskeletal protein filamin A cause diverse malformations in humans. Nat Genet 33:487-491. https://doi.org/ $10.1038 / \mathrm{ng} 1119$

6. Zenker M, Rauch A, Winterpacht A, Tagariello A, Kraus C, Rupprecht T, Sticht H, Reis A (2004) A dual phenotype of periventricular nodular heterotopia and frontometaphyseal dysplasia in one patient caused by a single FLNA mutation leading to two functionally different aberrant transcripts. Am J Hum Genet 74: 731-737. https://doi.org/10.1086/383094

7. Kyndt F, Gueffet JP, Probst V, Jaafar P, Legendre A, Le Bouffant F, Toquet C, Roy E, McGregor L, Lynch SA, Newbury-Ecob R, Tran V, Young I, Trochu JN, Le M, Schott JJ (2007) Mutations in the Gene Encoding Filamin A as a Cause for Familial Cardiac Valvular Dystrophy. Circulation 115:40-49. https://doi.org/10.1161/ CIRCULATIONAHA.106.622621

8. Gargiulo A, Auricchio R, Barone MV, Cotugno G, Reardon W, Milla PJ, Ballabio A, Ciccodicola A, Auricchio A (2007) Filamin $\mathrm{A}$ is mutated in X-linked chronic idiopathic intestinal pseudoobstruction with central nervous system involvement. Am J Hum Genet 80:751-758. https://doi.org/10.1086/513321

9. Puche A, Rodriguez T, Domingo R, Casas C, Vicente T, MartinezLage JF (1998) X-linked Subcortical laminar heterotopia and lissencephaly: a new family. Neuropediatrics 5:276-278. https:// doi.org/10.1055/s-2007-973575

10. De Wit MCY, Tiddens HAWM, de Coo IFM, Mancini GMS (2010) Lung disease in FLNA mutation: confirmatory report. Eur J Med Genet 54:299-300. https://doi.org/10.1016/j.ejmg.2010.12.009

11. Masurel-Paulet A, Haan E, Thompson EM, Goizet C, ThauvinRobinet C, Tai A (2011) Lung disease associated with periventricular nodular heterotopia and an FLNA mutation. Eur J Med Genet 54:25-28. https://doi.org/10.1016/j.ejmg.2010.09.010

12. Lord A, Shapiro AJ, Saint-Martin C, Claveau M, Melancon S, Wintermark P (2014) Filamin a mutation may be associated with diffuse lung diease mimicking bronchopulmonary dysplasia in premature newborns. Respir Care 59:171-177. https://doi.org/10. 4187/respcare.02847

13. Bickel S, Siefman M, Eid NS (2015) Interstitial lung disease, bcronchiectasis, and asthma in a patient with filamin A, alpha (FLNA) mutation. Am J Respir Crit Care Med 191:A5487 
14. Eltahir S, Ahmad KS, Al-Balawi MM, Bukhamsien H, AlMobaireek K, Alotaibi W, Al-Shamrani A (2016) Lung disease associated with filamin A gene mutation: a case report. J Med Case Rep 10:97. https://doi.org/10.1186/s13256-016-0871-1

15. Shelmerdine SC, Semple T, Wallis C, Aurora P, Moledina S, Ashworth MT, Owens CM (2017) Filamin A (FLNA) mutationa newcomer to the childhood interstitial lung disease (ChILD) classification. Pediatr Pulmonol 52:1306-1315. https://doi.org/10. 1002/ppul.23695

16. Burrage LC, Guillerman RP, Das S, Singh S, Schady DA, Morris SA, Walkiewicz M, Schecter MG, Heinle JS, Lotze TE, Lalani SR, Mallory GB (2017) Lung transplantation for FLNA-associated progressive lung disease. J Pediatr 186:118-123. https://doi.org/10. 1016/j.jpeds.2017.03.045

17. Kinane TB, Lin AE, Lahoud-Rahme M, Westra SJ, Mark EJ (2017) Case 4-2017: A 2 month-old girl with growth retardation and respiratory failure. N Engl J Med 376:562-574. https://doi.org/10.1056/ nejmcpc1613465

18. Kurland G, Deterding RR, Hagood JS, Young LR, Brody AS, Castile RG, Dell S, Fan LL, Hamvas A, Hilman BC, Langston C,
Nogee LM, Redding GJ (2013) An official American Thoracic Society clinical practice guideline: classification, evaluation, and management of childhood interstitial lung disease in infancy. Am J Respir Crit Care Med 188(3):376-394. https://doi.org/10.1164/ rccm.201305-0923ST

19. Bush A, Cunningham S, de Blic J, Barbato A, Clement A, Epaud R, Hengst M, Kiper N, Nicholson AG, Wetzke M, Snijders D, Schwerk N, Griese M (2015) European protocols for the diagnosis and initial treatment of interstitial lung disease in children. Thorax 70:1078-1084. https://doi.org/10.1136/thoraxjnl-2015-207349

20. O'Reilly R, Kilner D, Ashworth M, Aurora P (2015) Diffuse lung disease in infants less than 1 year of age: histopathological diagnoses and clinical outcome. Pediatr Pulmonol 10:1000-1008. https:// doi.org/10.1002/ppul.23124

21. Sheen VL, Feng Y, Graham D, Takafuta T, shapiro SS, Walsh CA (2002) Filamin A and Filamin B are co-expressed within neurons during periods of neuronal migration and can physically interact. Hum Mol Genet 23:2845-2854. https://doi.org/10.1093/hmg/11. 23.2845 